\title{
TESTIMONIO DE DÉCADAS DE COLABORACIÓN CON EL PROF. HARVEY*
}

\author{
Míkel de Epalza \\ Universidad de Alicante
}

Es costumbre, cuando uno participa en un volumen de homenaje a una personalidad cultural, especialmente tratándose de un investigador universitario como el Prof. Leonard Patrick Harvey, emérito de las universidades de Londres y Oxford, que se busque un tema de investigación propia que tenga relación con los temas que también ha cultivado el homenajeado.

Es evidente que lo que reúne nuestros respectivos estudios, de Harvey y míos, son los mudéjares y moriscos, esas "minorías" de musulmanes de las sociedades medievales y renacentistas esp añolas. Específicamente, hispanistas y arabistas en grados diversos, nos hemos interesadop or los escritos en castellano que esos musulmanes hisp anohablantes produjeron, tanto en las sociedades de la Península Ibérica como en su exilio, en diversos países, especialmente en el Magreb árabe y en otros países del inmenso Imperio Otomano, que gobernaba al menos la mitad de las regiones costeras del Mediterráneo, desde Argelia a los Balcanes. Pero el tema de mi investigación es tan puntual, en este volumen de homenaje, sobre «el santo protector de los moriscos en Tunicia» ${ }^{1}$, y mis relaciones y las de los profesores de la Universidad de Alicante con el prof. Harvey son tan amplias, que he preferido desligar esta dedicatoria del inicio de mi trabajo para escribir unas pocas páginas especiales de «Testimonio de décadas de colaboración con el Prof. Harvey».

Conocí al Prof. Harvey personalmente en Oviedo, en el congreso que reunía por vez primera a la may oría de los investigadores mundiales sobre mudéjares y moriscos². El profesor

\footnotetext{
* $\quad$ Este estudio se ha realizado en el marco del proyecto de investigación Edición digital de los textos en español de los mudéjares y moriscos y su contexto historiográfico, con la referencia BFF2002-02497, del Plan Nacional de Investigación Científica, Desarrollo e Innovación Tecnológica, cofinanciado con FEDER y concedido en el año 2002.
}

1. Ver M. de Epalza, «Sidi Bulgaiz, protector de los moriscos exiliados en Túnez (s. XVII). Nuevos documentos traducidos y estudiados», en este mismo volumen de Sharq Al-Andalus. Estudios Mudéjares y Moriscos, vol.16-17, pp. 141-172.

2. Los trabajos de esa reunión científica se publicaron en un volumen de Actas del Coloquio Internacional sobre Literatura Aljamiada y Morisca. Departamento de Filología Románica de la Facultad de Filosofía y Letras de la Universidad de Oviedo. 10 al 16 de julio de 1972, Madrid, Editorial Gredos (Colección de literatura española aljamiado-morisca, CLEAM, vol. 3) [Colección dirigida por Álvaro Galmés de Fuentes], 1978. La historia subsiguiente de los encuentros de “mudejaristas y moriscólogos” y sus principales producciones en diversos centros internacionales de investigación, en las dos décadas siguientes, han sido presentados en M. de EPALzA, «La moriscología como ciencia histórica en la actualidad», en ID. (dir.), L'Expulsió dels moriscos: conseqüències en el món islàmic i en el món cristià. Congrés internacional. 380 aniversari de l'expulsió dels moriscos (Sant Carles de la Ràpita, 5-9 de desembre de 1990), Barcelona, Generalitat de Catalunya. Departament de Cultura (Col·lecció Actes de Congressos, $n^{\circ}$. 4), 1994, 9-15. 
Harvey participó en una ponencia con un trabajo sobre el Mancebo de Arévalo (1er tercio del siglo XVI) ${ }^{3}$, el autor seguramente más original de esa literatura musulmana en español y de los más importantes -con Içe de Gebir, de Segovia (mediados del XV), con los autores granadinos de alrededor de los documentos del Sacromonte de Granada, con el o los autores anónimos del Evangelio de San Bernabé, con el o los autores anónimos de la traducción toledana del Corán del manuscrito de 1606 y con algunos de los escritores del exilio (princip ios del XVII)-. Yo participé con un trabajo global sobre los moriscos en Túnez (propiamente en todo el territorio tunecino) ${ }^{4}$, presentando un proyecto de libro y a realizado y que se publicaría el año siguiente, también con la colaboración del profesor Harvey ${ }^{5}$. Ese artículo mío de las Actas... de Oviedo sería reeditado más tarde en otra miscelánea sobre el mismo tema que el del Receuil d'Études... ${ }^{6}$.

En Oviedo y en 1972 el profesor Harvey era y a una autoridad consagrada en los estudios sobre la literatura de mudéjares y moriscos, con su tesis inédita y tantas veces citada ${ }^{7}$ y era muy conocido por su generosidad en ay udar con su ciencia a colegas del mundo entero. Yo era un recién llegado a la “moriscología”, desde las polémicas islámicas anticristianas andalusíes, magrebíes y moriscas- de mi tesis doctoral ${ }^{8}$, y por un estudio de la documentación archivística francesa sobre los moriscos o andalusíes tunecinos del siglo XVII ${ }^{9}$.

3. L. P. HARVEY, «El mancebo de Arévalo y la literatura aljamiada», Actas..., 20-43.

4. M. de Epalza, «Trabajos actuales sobre la comunidad de moriscos refugiados en Túnez, desde el siglo XVII a nuestros días», Actas..., 427-445.

5. M. de Epalza - R. Petrt (edits.), Receuil d’Études sur les Moriscos Andalous en Tunisie, Madrid, ed. Dirección General de Relaciones Culturales, 1973.

6. Slimane-Mostafa ZBiss - Abdel-Hakim Gafsi - Mohiedine BoughanMi - M. de Epalza, Études sur les Morisques Andalous, Túnez, ed. Institut National d’Archéologie et d’Art (col. Études Hispano Andalouses, 3), 1983, 229-241.

7. L. P. HARVeY, The literary Culture of the Moriscos (1492-1609): a Study based on the extant mss. in Arabic and Aljamía, Oxford, 1958.

8. Ver mi tesis M. de Epalza, La Tuhfa, autobiografía y polémica islámica contra el cristianismo, de 'Abdallâh al-Truchimán (Fray Anselm Turmeda), Universidad de Barcelona, 1967, que resumí en un folleto publicado por esa Universidad, Barcelona, 1973, y de la que publiqué un capítulo en francés « Notes pour une histoire des polémiques antichrétiennes dans l’Occident musulman», Arabica, Leiden, XVIII/1, 1971, 99-106, y en su totalidad en Roma, ed. Accademia Nazionale dei Lincei, 1971 (redición, con nuevo prólogo de María Jesús Rubiera Mata e introducción bibliográfica, en Madrid, ed. Hiperión, 1992, con el título Fray Anselm Turmeda ('Abdallāh al-Tar ŷumān) y su polémica islamo-cristiana. Edición, traducción y estudio de la Tuhfa).

9. M. de Epalza, «Moriscos y andalusíes en Túnez en el siglo XVII», Al-Andalus, Madrid, XXIV, 1969, 247-327, presentado y traducido al francés, sin los índices, en Receuil d’Études..., 150-186. 
De aquel primer encuentro científico nacería una colaboración de al menos tres décadas. Era natural, p or tanto, que le pidiera participara en el Receuil d'études..., petición a la que contestó p ositivamente, con su proverbial amabilidad. Nos ofreció un pasaje de su famosa tesis doctoral, que traducimos al francés ${ }^{10}$.

Luego coincidimos en tribunales de tesis doctorales ${ }^{11} \mathrm{y}$, sobre todo, en congresos internacionales de nuestras respectivas y tantas veces comunes especialidades. Los temas de los encuentros y de nuestras aportaciones indican bien unos mismos intereses científicos comunes, aunque con temas diferentes y también con métodos no siempre iguales, evidentemente. Esas ocasiones de encuentro eran también una mutua satisfacción de compartir intereses y descubrimientos científicos, como los expresaba muy bien Harvey en una carta que me envió: «Estas reuniones han sido para mí muy importantes. Uno se siente muy aislado en esta esp ecialidad en Gran Bretaña, y los contactos intelectuales y humanos ${ }^{12}$ son al fin y al cabo muy importantes $»^{13}$.

Los encuentros tunecinos organizados por el profesor Abdeljelil Temimi nos reunieron al menos dos veces. En 1986 era alrededor de la literatura morisca ${ }^{14}$, en donde Harvey habló del vocabulario de dos calendarios moriscos, textos muy interesantes para apreciar cómo los musulmanes islamizaban en español su categoría o visión sagrada del tiemp o, en la España cristiana del Siglo de Oro ${ }^{15}$, y yo ya analizaba las técnicas de traducción de los textos árabes islámicos a una lengua tan cristianizada como el castellano cuando trata de temas religiosos ${ }^{16}$. En 1989 era alrededor de las prácticas religiosas de los mudéjares y moris $\cos ^{17}$, donde Harvey expuso los principales ritos islámicos que practicaban esos musulmanes

10. L. P. Harvey, «Textes de littérature religieuse des Moriscos tunisiens», en M. de Epalza - R. Petit (dirs.), o. c., pp. 199-204.

11. Como en la Universidad de Oviedo, en las tesis doctorales de María José Fernández FERnÁNDEZ, 'Libro de los castigos' (Ms. aljamiado $n^{\circ} 8$ de la B. de la Junta. Edición, estudio lingüístico, glosario y notas, 1987, aún inédita, y de Gregorio FonSECA ANTUÑA, 'Sumario de la relación y ejercicio espiritual sacado y decla rado por el Mancebo de Arévalo en lengua castellana' (Ed. y estudio del ms. B. N. M. Res 245), 1987, recientemente editada, Madrid, ed. Fundación Menéndez Pidal (Col. CLEAM, vol. 11), 2002.

12. El subrayado es de Harvey.

13. Carta del 17-1-89.

14. Abdeljelil темімI (dir.), La littérature aljamiado-morisque : hybridisme linguistique et univers discursif. Les actes de la première table ronde du Comité International d'Études Morisques, Túnez, ed. Centre de Recherches en Bibliothéconomie et Sciences de l’ Information, vol. 13, 1986.

15. L. P. HARVEY, «The terminology of two hitherto unpublished morisco calendar texts», en A. TEMIMI (dir.), La littérature aljamiado-morisque..., 65-83.

16. M. de Epalza, «Un manuscrito narrativo normativo árabe y aljamiado: problemas lingüísticos, literarios y teológicos de las traducciones moriscas», en A. Temimi (dir.), La littérature aljamiado-morisque..., $35-45$.

17. A. Temimi (dir.), Las prácticas musulmanas de los moriscos andaluces (1492 - 1609). Actas del III Simposio Internacional de Estudios Moriscos, Zaghouan, ed. CEROMDI, 1989. 
esp añoles ${ }^{18}$ y yo las comp araba en las polémicas con las creencias y prácticas religiosas cristianas de la época ${ }^{19}$.

Por supuesto que cuando éramos nosotros, en la Universidad de Alicante o fuera de ella, los que organizábamos encuentros de tema morisco, el profesor Harvey era un invitado muy ap reciado. Así le invitamos al congreso internacional sobre la expulsión de los moriscos, celebrado en la localidad catalana de Sant Carles de la Ràpita ${ }^{20}$, donde el profesor Harvey tuvo una ponencia magistral sobre la política internacional de los moriscos ${ }^{21}$ y yo expuse en la lección inaugural las dimensiones de la actividad científica actual de investigación sobre los moriscos ${ }^{22}$, con otros muchos investigadores de temas afines, entre ellos algunos investigadores más jóvenes de la Universidad de Alicante, como el profesor Luis-Fernando Bernabé Pons ${ }^{23}$ y la profesora Eva Lapiedra $^{24}$.

Cinco años más tarde, en 1995, era la catedrática María Jesús Rubiera Mata y, bajo su dirección, un y a numeroso equipo de la Universidad de Alicante -y de otros orígenes-, los que nos reuníamos en Alicante para estudiar La Voz de los Mudéjares y Moriscos ${ }^{25}$. El profesor Harvey exp onía uno de sus últimos descubrimientos textuales, donde creía ver mencionado el principio islámico de la taqiyya (disimulo o simulación religiosa ante el peligro), del que se había escrito mucho pero que no estaba documentado directamente, en la situación de p eligro en que los moriscos vivían su fe islámica en las sociedades cristianas del siglo $\mathrm{XVI}^{26}$. Arabistas, pero también algún hispanista y germanista de la Universidad de Alicante, le acompañábamos en el volumen de Actas que se publicó en nuestra revista Sharq Al-Ándalus. Estudios Mudéjares y Moriscos: Rubiera Mata, presentando el volumen e identificando algunas afirmaciones

18. L. P. Harvey, «Los moriscos y los cinco pilares del Islam», en A. Temimi (dir.), Las prácticas musulmanas..., 93-97.

19. M. de EpalzA, «Rites musulmans opposés aux rites chrétiens dans deux textes de morisques tunisiens: Ibrahim Taybili et Ahmad Al-Hanafi», en A. TEMIMI (dir.), Las prácticas musulmanas..., 71-74.

20. M. de Epalza (dir.), L’Expulsió dels moriscos:...

21. L. P. HaRveY, «The Moriscos and their international relations», en M. de Epalza (dir.), L'Expulsió dels moriscos..., 135-139.

22. M. de EPALZA, « La moriscología...

23. Luis-Fernan do BERnABÉ Pons, «Sociolingüística de los moriscos expulsados: árabe, catalán, valenciano, castellano», en M. de EpAlZA (dir.), L’Expulsió dels moriscos..., 380-383.

24. Eva LApIEDRA, «Los moriscos en Libia», en M. de E palza (dir.), L’Expulsió dels moriscos..., 369-371.

25. María Jesús Rubiera Mata (dir.), Congreso "La voz de los mudéjares y moriscos”. Alicante, 23 -29 de marzo de 1995, en Sharq Al-Andalus. Estudios Mudéjares y Moriscos, Teruel-Alicante, 12, 1995.

26. L. P. HARVEY, «Una referencia explícita a la legalidad de la práctica de la ta q⿳亠丷厂ya por los moriscos», en M. J. Rubiera Mata (dir.), Congreso “La voz de..., 561-563. 
autobiográficas que hasta entonces habían parecido extrañas en los escritos del Mancebo de Arévalo, explicándolas en particular por su triple origen religioso -judío converso de origen, cristiano de educación castellana y musulmán de adopción, aragonizado lingüísticamente por sus copistas- ${ }^{27}$; Bernabé Pons, que estudia a uno de esos copistas navarro-aragonés del Mancebo de Arévalo ${ }^{28}$; Franco Sánchez, sobre un relato de viaje granadino en árabe, de finales del siglo $\mathrm{XV}^{29}$; Zanón, que analiza algunas características del fondo de manuscritos de mudéjares y moriscos, en árabe y en español, encontrados a fines del XIX en Almonacid de la Sierra (Zaragoza) ${ }^{30}$; Cutillas Ferrer, sobre un singular texto de doctrina y prácticas chiíes ${ }^{31}$; Auladell, sobre los moriscos en el teatro del XVII ${ }^{32}$; Valero Cuadra, sobre diversas variantes y trasfondo literario de un exitoso relato de las letras hispánicas ${ }^{33}$; y yo mismo presentando unos textos, aún no editados científicamente, ni suficientemente estudiados, de mudéjares y moriscos ${ }^{34}$. Con esta ocasión el profesor Harvey se manifestaba, una vez más, en sintonía y en científica vinculación con un equip o de investigación alicantino y a bastante rico y variado en temas de literatura de mudéjares y moriscos, temas que Harvey llevaba casi medio siglo estudiando.

También le hicimos invitar en 1996, la Dra. María Jesús Rubiera y yo, como miembros del Comité Científico que preparábamos, en el VII Simp osio Internacional de Mudejarismo, el siguiente Simposio de $1999^{35}$. Su ponencia presentó la literatura musulmana en español (“aljamiado”), especialmente la traducción del Corán al castellano por Içe de Gebir y Juan de

27. M. J. Rubiera MAtA, «Presentación de este número» y «Nuevas hipótesis sobre el “Mancebo de Arévalo”», en M. J. RuBieRA MatA (dir.), Congreso “La voz de..., 5-6 y 315-323.

28. L.-F. Bernabé Pons, « Nuevas hipótesis sobre la pers on alidad de Baray de Reminyo», en M. J. RuBIERA MATA (dir.), Congreso "La voz de..., 299-314.

29. Francisco Franco SÁnchez, «Los mudéjares, según la riḥla de Ibn Aṣ-Sabbāḥ (m. después 895/1490)», en M. J. Rubiera Mata (dir.), Congreso "La voz de..., 375-391.

30. Jesús ZANÓn, « Los estudios de lengua árabe de los moriscos aragoneses a través de los manuscritos de la Junta», en M. J. RuBieRA MATA (dir.), Congreso "La voz de..., 363-374.

31. José Francisco CUTILlas FerRer, «Un texto chií en castellano, del XVII, en el universo cultural islámico de los moriscos expulsados», en M. J. RubieRa Mata (dir.), Congreso "La voz de..., 393-400.

32. Miguel Ángel AulAdell, «Los moriscos, sociedad marginada en el teatro español del siglo XVII», en M. J. RuBiera MATA (dir.), Congreso "La voz de..., 401-412.

33. Pino Valero Cuadra, «La leyenda de la doncella Carcayona», en M. J. Rubiera Mata (dir.), Congreso "La voz de..., 349-361.

34. M. de Epalza, «La voz oficial de los musulmanes hispanos, mudéjares y moriscos, a sus autoridades cristianas: cuatro textos, en árabe, en castellano y en catalán-valenciano», en M. J. RuBIERA MATA (dir.), Congreso "La voz de..., 279-297.

35. Ver la publicación de los dos volúmenes de Actas. VIII Simposio Internacional de Mudejarismo. De mudéjares a moriscos: una conversión forzada. Teruel, 15-17 de septiembre de 1999, Teruel, ed. Centro de Estudios Mudéjares. Instituto de Estudios Turolenses, 2002. 
Segovia (mediados del XV) y el estilo y unos ejemplos concretos de textos del Mancebo de Arévalo $^{36}$. En 1999 se habían presentado las actas de aquel Simposio anterior, de 1996², en las que se publicaban las ponencias de los arabistas Luis Fernando Bernabé Pons y María-Jesús Rubiera Mata, sobre los estudios de la lengua de mudéjares y moris $\cos ^{38}$, y Míkel de Epalza y Abdel-Hakim Gafsi Slama, sobre los restos documentados del español hablado por los moriscos exiliados a Túnez en el XVII y por sus descendientes los andalusíes hasta nuestros días ${ }^{39}$. Además también se publicaban las ponencias y trabajos de otros investigadores medievalistas de la Universidad de Alicante, como José Hinojosa, sobre las actividades económicas de los mudéjares en general ${ }^{40}$, y José Antonio Barrio y José Cabezuelo, sobre sus actividades económicas en una comarca concreta de la actual provincia de Alicante ${ }^{41}$.

La relación científica entre la Universidad de Alicante y su grupo de investigadores sobre los mudéjares y moriscos con el profesor Leonard Patrick Harvey se hizo aún más estrecha al incluirle en los trabajos del proyecto oficial de investigación, del Ministerio de Educación, Ciencia y Cultura, sobre «Concordancias léxicas lematizadas de la obra del Mancebo de Arévalo», realizado entre 1997 y 2001². Sus visitas a Alicante y su ilusión por ver proseguirse unas investigaciones sobre el Mancebo, que él había iniciado casi medio siglo antes, fueron fuente de muy interesantes intercambios, donde manifestó una vez más su generosidad científica y apertura intelectual ante nuevas metodologías y nuevos descubrimientos, sobre unos textos de aún realmente difícil interpretación y que él llevaba tantos años estudiando. Esas investigaciones siguen dando nuevos frutos y es de esperar que aún salgan mayores novedades, especialmente alrededor del personaje señero del Mancebo de

36. L. P. HARVEY, « La literatura aljamiada», Actas. VIII Simposio..., vol. II, 849-859.

37. VII Simposio Internacional de Mudejarismo (Teruel. 19-21 de septiembre de 1996). Actas, Teruel, ed. Centro de Estudios Mudéjares. Instituto de Estudios Turolenses, 1999.

38. L.-F. Bernabé Pons - M.-J. Rubiera MatA, «La lengua de mudéjares y moriscos. Estado de la cuestión», en VII Simposio Internacional de Mudejarismo..., 599-631.

39. M. de EpAlza - A.-H. Gafsi Slama, «Léxico y onomástica hispánicos de los moriscos, conservados en Tunicia», en VII Simposio Internacional de Mudejarismo..., 633-641.

40. José Hinojosa Montalvo, «La economía de los mudéjares: estado de la cuestión», en VII Simposio Internacional de Mudejarismo..., 7-41.

41. Juan Antonio Barrio Barrio - José Cabezuelo Pliego, «Rentas y derechos señoriales de las morerías del valle de Elda a finales del siglo XV», en VII Simposio Internacional de Mudejarismo..., 43-53.

42. Programa Sectorial de Promoción General del Conocimiento, de la Dirección General de Enseñanza Superior, Secretaría de Estado de Universidades, Investigación y Desarrollo, Ministerio de Educación y Cultura, proyecto ${ }^{\circ}$ PB 1997-0116. 
Arévalo ${ }^{43}$.

Este volumen de homenaje al prof. Harvey no es más que el principio de un proyecto mucho más ambicioso, hecho y a realidad en parte: el recoger su obra escrita, como la de todos los estudiosos en temas de mudéjares y moriscos, en Int ernet, en edición digital. En este breve recuento de las actividades compartidas con el profesor Harvey y los actuales investigadores sobre mudéjares y moriscos, en la Universidad de Alicante, hay que mencionar, por tanto, la inclusión y a de alguno de sus trabajos en el Portal Literatura de Mudéjares y Moriscos», fundado y dirigido por la catedrática de Estudios Árabes e Islámicos María Jesús Rubiera Mata, en el marco de la Biblioteca Virtual «M iguelde Cervantes Saavedra» (BIMICESA), que ha introducido y está introduciendo en Internet las principales obras y estudios de la literatura española e hispanoamericana, incluida en una sección la literatura en lengua catalana y en preparación la de la lengua vasca o euzkera. Es una obra ingente, que y a integra anualmente millones de consultantes o lectores y permite difundir mundialmente los textos antiguos y las investigaciones más recientes ${ }^{44}$. En ese portal, que fue presentado a los especialistas reunidos en Teruel con ocasión del IX Simposio Internacional de Mudejarismo (sep tiembre 2002) y que se va llenando a medida de las disp onibilidades del personal que se dedica a esa tarea, van entrando también los trabajos del prof. Harvey, como los de otros investigadores interesados y de éste y los demás volúmenes de la revista Sharq Al-Ándalus. Estudios Mudéjares y Moriscos.

\section{RESUMEN}

Presentación de las actividades del profesor británico Leonard Patrick Harvey (profesor en Londres y Oxford) y especialista en literatura en español de los musulmanes españoles (aljamiados) de los siglos XV-XVII, en relación con los profesores e investigadores de la Universidad de Alicante, que le dedican un volumen de homenaje de su revista Sharq Al-Andalus. Estudios Mudéjares y Moriscos (actualmente editada entre Teruel y Alicante), y en edicióndigital en la Biblioteca Virtual Miguel de Cervantes Saavedra (BIMICESA), http: //cervantesvirtual.com/portal/lmm.

43. Ver ya L. P. Harvey, «El Mancebo de A révalo and his creatises on islamics faith and practice», Journal of Oriental and Islamic Studies, Oxford, 10/3, 1999, 249-276; M. J. RubIERA MATA, «El Islam cristianizado de los moriscos castellanos en época de Carlos V», en Carlos V y la quiebra del humanismo político en Europa (1530-1558), Madrid, ed. Sociedad Estatal para la Conmemoración de los Centenarios de Felipe II y Carlos V, 2001, vol. I, 469-485; ID., «El judeo-converso y morisco “ Mancebo de Arévalo”, autor de las tres culturas hispánicas (s. XVI)», Europa e Islam tra i secoli XIV e XVI. Europe and Islam between 14th and 16th centuries, Napoli, ed. Istituto Universitario Orientale (Collana "Matteo Ripa”, XVIII), t. II, 2002, 839-856; y L.-F. BERnabé Pons, «Un “nuevo” texto del Mancebo de Arévalo», en Sharq Al-Ándalus. Estudios Mudéjares y Moriscos, Teruel-Alicante, 14-15, 1997-1998, 469-470; ID. «Un tiempo para los moriscos: el calendario islámico del Mancebo de Arévalo», en M. J. RuBiERA MatA (coord.), Carlos V, los moriscos y el Islam, Madrid, ed. Sociedad Estatal... - Universidad de Alicante, 2001, 91-101; ID., «El calendario musulmán del Mancebo de Arévalo», en este mismo volumen de la revista Sharq Al-Ándalus..., pp. 241-265.

44. Sitio en Internet vhtt: cervantesvirtual.com//portal/lmm. 
Palabras clave: Alicante, aljamiado, Harvey, Moriscos.

\begin{abstract}
Introduccion to the activities of the British Professor Leonard Patrick Harvey (Professor at London and Oxford), a specialist on the Spanish literature or aljamiados written by Spanish Muslims in the 15th.-17th. centuries, in relation with the lecturers and researchers of the University of Alicante, who have dedicated him a commemorative volume of their review Sharq Al-Andalus. Estudios Mudéjares yMoriscos (currently published in Teruel and Alicante), and the digital edition of which is available at the Miguel de Cervantes Saavedra Virtual Library (BIM ICESA), http: //cervantesvirtual.com/p ortal/lmm.
\end{abstract}

Key words: Alicante, aljamiado, Harvey, Moriscos. 